\title{
GESTÃO PEDAGÓGICA DE CURSOS DE LICENCIATURA EM UMA UNIVERSIDADE PÚBLICA: CONTRIBUIÇÕES PARA UMA REFLEXÃO*
}

\author{
Glaucia Maria da Silva, \\ da Universidade de São Paulo, Ribeirão Preto \\ Noeli Prestes Padilha Rivas, \\ da Universidade de São Paulo, Ribeirão Preto
}

\begin{abstract}
REsUMo: Este trabalho apresenta reflexões acerca de experiências na coordenação de cursos de graduação de formação de professores no contexto de uma universidade pública brasileira, enfocando elementos facilitadores e elementos limitantes de construção de um processo coletivo, tendo os projetos pedagógicos dos cursos como instrumentos de gestão. Entre os elementos facilitadores são apontados e analisados alguns dispositivos legais e cursos de formação docente, promovidos pela universidade, que enfocam o tema da gestão. Quanto aos limites, são mencionados, dentre outros, dificuldades de construção do trabalho coletivo, sobrecarga de trabalho dos docentes, condições de ofertas dos cursos de graduação, valorização e prioridade da pesquisa em detrimento do ensino.

Palavras-chave: Gestão Pedagógica na Educação Superior. Coordenação de Cursos de Graduação. Currículo. Formação de Professores.
\end{abstract}

\section{INTRODUÇÃO}

Este texto analisa o processo de gestão de cursos de graduação no contexto de uma universidade pública, a partir da atuação da Coordenação de Curso (COC), que tem como principais atividades a coordenação, implementação e avaliação do projeto pedagógico do curso. Trata-se de estudo reflexivo, no qual as autoras analisam suas experiências em

* Artigo recebido em 11/05/2011 e aprovado em 12/07/2011. 
coordenação de cursos de graduação, modalidade de licenciatura na área de Educação (Pedagogia) e de Química, focalizando os elementos facilitadores e os limites de construção de um processo de gestão democrática e coletiva. As atuais políticas nacionais de graduação indicam a necessidade de haver mudanças no ensino, como a participação dos docentes na elaboração e implementação do projeto pedagógico de seus cursos, o incentivo às práticas de estudos independentes e às atividades que instiguem a investigação e o desenvolvimento da capacidade crítica do estudante, promovendo autonomia profissional e intelectual, a formação integral, o atendimento à demanda social, o fortalecimento da articulação teoria-prática e da interdisciplinaridade, dentre outras. Essas indicações aliadas à expansão nacional e internacional do campo de saber da pedagogia universitária e ao compromisso e interesse de muitos docentes da universidade, em relação ao ensino de graduação, vêm constituindo-se em elementos facilitadores de mudanças.

O texto apresenta três momentos que se interligam por meio de um eixo gerador, que é a gestão de cursos de graduação na Universidade. No primeiro momento, aborda-se o contexto das políticas de gestão na universidade situando seu campo epistemológico, os ordenamentos legais e políticos da educação superior no Brasil e América Latina. Depois, analisa-se a gestão dos cursos de licenciatura em uma universidade pública pontuando os elementos facilitadores e limitantes do processo organizativo e pedagógico. Finaliza-se o artigo, elencando alguns eixos norteadores que balizam a tessitura de ações na área da gestão de cursos e que possibilitam a reflexão acerca da gestão pedagógica e da qualidade no Ensino Superior.

\section{APONTAMENTOS SOBRE A GESTÃO EDUCACIONAL NA EDUCAÇÃO SUPERIOR}

As universidades brasileiras, de uma forma geral, a partir do final da década de 1980, vêm buscando a qualificação da gestão pedagógica no ensino de graduação por meio de várias ações que se expressam, dentre outras, na elaboração e no acompanhamento dos projetos pedagógicos dos cursos de graduação. Nesse sentido, a expressão "gestão educacional" começa a ganhar força na literatura com a orientação de ações educacionais, significando o processo de gerir a dinâmica do sistema de ensino como totalidade e coordenação de instituições de ensino, em sintonia com as políticas educacionais públicas, tendo em vista a implementação de políticas educacionais e projetos pedagógicos fundamentados em princípios democráticos e participativos (LÜCK, 2010).

No campo das ciências sociais e humanas, essa situação gera perplexidade e tensão. Os ordenamentos internacionais (transnacionalização, gestão 
da educação superior) balizados fortemente pelo controle estatal afetam a relação estado/universidade, seja pela presença do estado avaliador (Neave, 1999), seja pela instauração de estratégias de mercado, de políticas públicas e de gestão (Dale, 1999; Afonso, 2000; Morosini e Morosini, 2006) na lógica da crise do Estado proposta por Santos (2004). Essa perspectiva globalizada se estende à educação e ao campo do conhecimento, cujo discurso assenta-se na concepção de sociedade da informação e comunicação, na fragmentação do conhecimento como instrumentalização e sua concepção como commodities.

Reconhece-se, atualmente, que há uma diversidade de modelos de universidades e tipos de conhecimento, em detrimento do modelo tradicional de universidade e suas antigas funções que congregava para si o monopólio de construção do conhecimento. Delanty (2001) aponta que a universidade pós-moderna contesta o conhecimento global e reconhece a emergência de conhecimentos locais. Existem muitos tipos de conhecimento e um crescente ceticismo sobre a afirmação de universalismo construído sobre valores da racionalidade cognitiva (MOROSINI e MOROSINI, 2006). Nessa transição entre o moderno e o pós-moderno, paralelo à desreferencialização do conhecimento trazido pela pós-modernidade, os países desenvolvidos propõem como modelo a Universidade Sustentável que busca fortificar elementos institucionais mantenedores da transformação, paralelo a novas mudanças, tais como "diversificação da base financeira; fortificação do centro diretivo; expansão do desenvolvimento periférico; estímulo à comunidade acadêmica; e integração da cultura empreendedora" (Morosini e Morosini 2006, p. 3).

O neoliberalismo, na forma como aparece no campo educacional, não só substitui a reflexão teórica pela afirmação "de um catálogo de princípios e de verdades irreversíveis de caráter doutrinário" (Frigoto e Ciavatta, 2001 , p. 13), mas enseja novos modelos de universidade na perspectiva da produtividade, passando a ser arquitetada como parte do problema econômico de cada país (Sguissardi, 2004). Enfocando a Universidade brasileira em seus desafios políticos e epistemológicos, Cunha (2009) comenta que a complexidade do contexto no fim do século XX e começo do século XXI, marcada por ideologias neoliberais e visões conservadoras, levou à reorientação dos sistemas educacionais, a fim de valorizar o mercado como eixo definidor de políticas nessa área. Além disso, buscou-se uma pedagogia que, influenciada por esse processo, também assumisse a parceria com processos produtivos como primeiro compromisso educativo. Chauí (2003) dialoga com este contexto quando destaca que a universidade está deixando de ser uma instituição, que se percebe inserida na divisão social e política e 
na busca de uma universalidade que lhe permita responder às contradições presentes na sociedade, para se tornar uma organização burocrática. Para a autora, a universidade direciona o currículo e os docentes à preparação de alunos para o mercado, perdendo sua principal característica de reflexão e de formação intelectual.

Os desafios para a gestão da educação pública, no atual contexto, são inúmeros e complexos. No Brasil, a gestão democrática da educação figura como norma jurídica na Constituição Federal de 1988 (CF, 5/10/1988), na Lei de Diretrizes e Bases da Educação Nacional (LDB, Lei n. 9.394/96, de 20/12/1996) e no Plano Nacional de Educação (PNE - Lei n. 10.127, 09/1/2001), mas sua regulamentação tem sugerido uma diversidade de interpretações que variam conforme o lugar e os agentes envolvidos.

Quando se constatam esforços efetivos para a melhoria do ensino, estes são localizados e pontuais, já que a demanda por força de trabalho com qualificações mais complexas não advém de todos os setores da economia brasileira, mas apenas de setores que competem com os segmentos mais inovadores e produtivos da economia mundial. Verifica-se a adequação do sistema educacional à heterogeneidade das demandas do sistema econômico, que aponta para a qualificação da força de trabalho não apenas no âmbito nacional, mas mundial. Como decorrência, e em razão da crescente mobilidade do capital, a educação deixou de ser uma questão nacional, tornando-se campo de disputa dos organismos transnacionais.

Bruno (2002), ao refletir sobre questões semelhantes a respeito da gestão democrática e contextos complexos, assinala que

melhorar a qualidade da educação vai muito além da promoção de reformas curriculares, implica, antes de tudo, criar novas formas de organização do trabalho na instituição escolar, que não apenas se contraponham às formas contemporâneas de organização e exercício do poder, mas que constituam alternativas práticas possíveis de se desenvolverem e de se generalizarem, pautadas não pelas hierarquias de comando, mas por laços de solidariedade, que consubstanciam formas coletivas de trabalho, instituindo uma lógica inovadora no âmbito das relações sociais. (p. 44)

Essas novas formas de organização do trabalho apontadas pela autora nos remete aos dispositivos político-sociais e legais que trazem à tona a necessidade da formação inicial e continuada não apenas de profissionais aptos para uma determinada atividade, mas de sujeitos historicamente situados, comprometidos socialmente. Nesse aspecto devem ser repensados os conhecimentos produzidos e suas articulações entre si e com a realidade, os modelos curriculares, as concepções e estratégias metodológicas 
e de avaliação utilizadas em salas de aula, enfim, deve ser retomada a intencionalidade das práticas educativas no contexto universitário. Esse repensar mostra-se desafiante e traz demandas específicas para a coordenação dos cursos de graduação, sendo fundamental a construção de processos de gestão pedagógica que ultrapassem a lógica burocrática e operacional, em direção a processos democráticos e coletivos.

A gestão de órgãos superiores dos sistemas de ensino e instituições educacionais é demarcada pelos processos sociais que contemplam contínuas interações de seus elementos plurais e diversificados (Lück, 2010), os quais estão relacionados aos objetivos institucionais. Assim, é importante ressaltar que as mudanças ocorrem mediante processo de transformação, caracterização pela produção de ideias, processos e estratégias promovidos pela mobilização do talento e energia internos e acordos consensuais.

Na universidade pública, em análise, tem havido a proposição de políticas e ações de valorização do ensino de graduação que buscam colocar na pauta cotidiana a atividade de ensino como função precípua da universidade que, aliada às atividades de pesquisa e extensão, possa contribuir para o avanço do conhecimento científico e cultural, respondendo às necessidades sociais. Todavia, essa possibilidade confronta-se com outras intencionalidades presentes no conjunto da Universidade, prioritariamente fundamentadas na lógica da produtividade. Enfocar a gestão do ensino e, de modo mais específico e restrito, a gestão pedagógica cotidiana dos cursos de graduação, foco deste texto, torna-se tarefa desafiante a ser aprendida, na medida em que se trata de proposta que busca extrapolar o cumprimento normativo e burocrático que faz funcionar o ensino, incorporando o processo reflexivo sobre o projeto de formação que se pretende implementar como cerne. Algumas questões (que modelo de sociedade se pretende construir e fortalecer; qual aluno se pretende formar; quais os fundamentos políticos, culturais, curriculares e pedagógicos que permeiam as práticas educativas relacionadas ao processo de ensino e aprendizagem) balizam os processos de tomada de decisão sobre o ensino nos cursos de graduação, para que não se perca o sentido do que se produz e o compromisso social da Universidade pública.

A partir de nossas experiências em comissões de coordenação de cursos de graduação, nas áreas de Educação e Química, apontamos alguns elementos facilitadores, fundamentados na literatura atual cujo enfoque centra-se no papel da gestão em uma universidade pública, tendo como pressuposto a perspectiva crítica da educação. Estes elementos, apesar do contexto tensionado no âmbito da sociedade e do papel da universidade, 
podem ser apontados como promotores de mudanças na gestão dos cursos de graduação e se referem aos dispositivos político-legais que trazem novos indicativos para a organização do ensino superior no Brasil, bem como impulsionam a revisão das práticas pedagógicas e implicações para a gestão.

O primeiro insere-se no âmbito das políticas macro e diz respeito à Conferência Regional de Educação Superior para a América Latina e Caribe (CRES/2008) a qual teve como objetivo analisar e propor políticas estratégicas para a educação superior da região, reafirmando o seu princípio de direito humano e bem público e social. No Brasil, o documento preparatório à Conferência Mundial de 2009 ressalta como prioridade a construção da "universidade socialmente relevante". O segundo refere-se à construção do Plano Nacional de Educação 2011-2020, incorporando ações de inclusão, de atendimento à diversidade, de promoção da igualdade e de gestão democrática na agenda da educação superior brasileira para o próximo decênio, a partir dos eixos: Currículo da educação superior; Expansão e democratização da educação superior; Financiamento da educação superior; Gestão e avaliação da educação superior; Formação e valorização dos profissionais da educação superior (CURY, 2009, p. 15).

O terceiro relaciona-se à Lei de Diretrizes e Bases da Educação Nacional (LDB - Lei n. 9.394/96) e Diretrizes Curriculares Nacionais (DCNs) para os cursos de graduação, fundamentando-se em parâmetros como construção coletiva do projeto pedagógico, flexibilidade, formação integral, incorporação de atividades complementares, interdisciplinaridade e articulação teoriaprática (Plano Nacional de Graduação, 1999).

Concordamos com Ferreira (2006), em relação ao compromisso da gestão que também se faz em sala de aula, no exercício da docência e da necessária diretividade para a consecução do planejado e organizado em sala de aula e nos espaços institucionais. Nesse sentido, a gestão da educação envolve a garantia de qualidade do processo educativo, considerando-se os determinantes políticos, sociais, culturais e educacionais.

\section{A GESTÃO DOS CURSOS DE LICENCIATURA: ELEMENTOS FACILITADORES}

A partir de 2008, houve uma mobilização da Pró-Reitoria de Graduação da Universidade de São Paulo que, por meio da formação de um grupo de trabalho constituído por docentes de diversos cursos e campos de saber, desenvolveu uma proposta de discussão e revisão da legislação interna acerca das atribuições e da organização das "Comissões de Coordenação de Curso" (CoC). Essa proposta, consubstanciada por meio da Resolução CoG n 5.500, de 13 de janeiro de 2009 (USP, 2009), possibilita às unidades de ensino com- 
porem comissões para acompanhar pedagogicamente o desenvolvimento dos cursos de graduação, tendo o projeto pedagógico do curso como instrumento do processo de gestão. Destaca-se, na elaboração deste documento, a intenção de promover, nos distintos cursos, a gestão pedagógica alicerçada em valores democráticos, sendo os docentes participantes dessas comissões responsáveis por viabilizarem espaços de discussão compartilhada sobre a construção cotidiana do projeto pedagógico dos cursos. O artigo $4^{\circ}$ dessa Resolução especifica que "a composição da CoC e os critérios da eleição de seus membros serão aprovados pelo CoG, a partir de proposta da Comissão de Graduação (CG) ratificada pela Congregação" da unidade responsável pelo curso de graduação. As atribuições da gestão da CoC estão definidas no artigo $2^{\circ}$ e, em sua maioria, tratam da implementação, da coordenação, do acompanhamento e da avaliação do projeto político-pedagógico do curso considerando-se as questões relacionadas ao currículo e ao aluno, bem como aos temas relacionados à inovação pedagógica. Para Veiga (2001), a execução de um projeto pedagógico necessita considerar alguns aspectos: que ele seja construído a partir da própria realidade, considerando os problemas existentes e as situações nas quais aparecem; que seja exequível, sendo previstas as condições necessárias ao seu desenvolvimento e à avaliação; que ele se construa e se implemente por ação articulada entre todos os envolvidos com a realidade da escola, sendo construído continuamente, pois ao mesmo tempo é produto e processo. Outro ponto que emerge como fundamental é perceber o projeto pedagógico como instrumento de gestão, o que implica tocar na necessidade de construção cotidiana do trabalho coletivo, sendo esse mais um importante desafio para as coordenações de curso. Esse desafio relaciona-se ao enfrentamento de se lidar com o predomínio do trabalho mais individualizado do docente universitário, bem como com as estruturas departamentais que acabam fragmentando o curso em disciplinas e, consequentemente, atingindo os docentes, pois estes perdem a visão de unidade que se tece pela interligação, pelo diálogo e pela negociação dos saberes, das experiências, dos sujeitos em suas intencionalidades na construção do curso.

Considerando que o foco deste trabalho centra-se na gestão de cursos de formação de professores, ressalta-se como um dos elementos facilitadores a implantação do Programa de Formação de Professores (PFPUSP) da USP, 2004, e a decorrente criação da Comissão Interunidades de Licenciatura (CIL) que trazem delineamentos para os projetos formativos dos cursos, os quais passam a se constituir em torno de valores, concepções e práticas comuns que não negam as diversidades, mas apontam para a construção de uma unidade possível. O PFPUSP tem por finalidade a formação 
inicial de professores para a educação básica, com capacidade científica e profissional, politicamente motivados a lidar com a diversidade da população atendida hoje pela escola básica brasileira. A concretização desse ideal requer a formação de um professor não apenas dotado de competência em sua área de saber, mas também capaz de compreender essa diversidade, de modo a corresponder às expectativas daqueles que frequentam a escola. Tal compreensão pressupõe o entendimento de que as respostas mais adequadas para cada comunidade escolar emergirão de um trabalho compartilhado e que deve ser objeto de discussão nos cursos de licenciatura/formação de professores. Na relação diversidade-unidade dos cursos, os processos de gestão podem ser fortalecidos.

Cabe ainda considerar que alguns cursos de formação dos próprios professores da universidade, promovidos pela Pró-Reitoria de Graduação e grupos de apoio pedagógico, vêm favorecendo a discussão e construção de conhecimentos sobre gestão de cursos pelos docentes envolvidos. Quanto aos limites para a construção da gestão pedagógica dos cursos, na direção apontada, mencionamos as dificuldades em articular as distintas instâncias de poder que estão implicadas nas decisões acerca do ensino de graduação nas unidades de ensino, essencialmente os departamentos. Nesse sentido, Sabadia (1998) apresenta uma experiência de coordenação de curso em uma universidade federal brasileira e aponta dificuldades institucionais, tais como: limitado apoio ao trabalho das coordenações por parte de departamentos no que se refere à infraestrutura, pessoal e participação no processo decisório; pouco reconhecimento da importância das coordenações pelas instâncias acadêmicas; ausência de representação das coordenações junto aos órgãos colegiados superiores; conflitos políticos e administrativos entre as coordenações e os departamentos no que diz respeito às questões pedagógicas, como mudança de currículo, designação de professores, aprovação de programas e oferecimento de disciplinas; falta de infraestrutura adequada para o funcionamento das coordenações. Essas dificuldades não são estranhas ao nosso contexto cotidiano e, provavelmente, enfrentálas, redimensioná-las e superá-las, na construção de outras relações, será imprescindível para o trabalho da Comissão Coordenadora de Curso.

A gestão possibilita superar o limite da fragmentação e da descontextualização, construindo pela perspectiva abrangente e interativa. Nesse sentido, a gestão constitui-se uma ação participativa (Lück, 2010). É a intencionalidade do que se quer fazer que orienta a direção da ação e os modos de organizar a execução. É ela que norteia o que se apresenta como desejado e necessário. Isso implica especificar determinada intenção de ações e fins 
almejados que se fundamentam naquilo que é valorizado por uma coletividade, em dado momento histórico, em uma determinada sociedade. Trata-se de uma proposta de trabalho que não se alicerça em interesses individualistas, mas no interesse comum de um grupo de profissionais que, ao definiremse no coletivo, orientam tanto o destino de sua instituição como o destino dos homens e das mulheres que formam, pois "um processo de gestão que construa coletivamente um projeto pedagógico de trabalho tem já, na raiz, a potência da transformação" (Ferreira, 2006, p. 113).

Nesse aspecto, torna-se importante refletir sobre as dificuldades de construção do trabalho coletivo. Zabalza (2004) refere-se aos "jogos de poder" presentes entre os distintos grupos culturais da universidade. Um dos limites relacionados à gestão a ser considerado refere-se ao desconhecimento da comunidade universitária em relação ao sentido pedagógico da gestão de curso, tendo em vista que predominam, historicamente, práticas burocratizadas. Além deste, destacam-se o horário de oferecimento do curso no período noturno; a baixa valorização da formação de professores; o perfil dos alunos que apresentam peculiaridades sociais e percursos escolares específicos (aluno trabalhador, limitado capital cultural, entre outros).

Tendo em vista a perspectiva de gestão democrática, envolvendo decisões coletivas, apresentamos nossa proposta com eixos de ações que, em um primeiro momento, subsidiam as ações das comissões de coordenação dos cursos de licenciatura, com o intuito de contemplar as atividades de gestão do ensino e configurá-las num outro patamar. É fundamental que um plano de gestão seja produto compartilhado por docentes e alunos que compõem a CoC-Licenciatura, para que realmente sejam construídas identidades coerentes com uma proposta de gestão democrática, viabilizando a efetivação das ações cotidianas, para além do cumprimento meramente dos aspectos burocráticos. Não basta que o Plano de Gestão das CoCs-Licenciatura seja conhecido apenas por seus integrantes, é necessário socializá-lo com a comunidade universitária diretamente implicada. A intenção é fortalecer o diálogo e a tomada de decisões coletivas, considerando o projeto pedagógico como instrumento de gestão que baliza a construção cotidiana do ensino acompanhamento e avaliação processual. Todos os eixos/ações propostos estão inseridos em permanente processo avaliativo do ensino, envolvendo o currículo, o processo ensino-aprendizagem e a própria gestão do curso de licenciatura.

Essa proposta considera o processo de acompanhamento e avaliação de cursos de graduação que vem sendo construídos, a partir da proposta institucional da Câmara de Avaliação da Pró-Reitoria de Graduação desde 2008 
e o Plano Trienal (2009 - 2011) de Metas e Ações para o Curso de Licenciatura em Química e Pedagogia que apontam problemáticas e ações percebidas e propostas.

A seguir, são delineados eixos norteadores/ações, que se desdobram em "desenvolvimento do currículo", "desenvolvimento do processo ensinoaprendizagem em sala de aula e cenários práticos", "gestão do ensino e formação pedagógica do corpo docente". Para cada eixo, organiza-se uma série de ações e formas de operacionalização.

\section{EIXOS NORTEADORES E TESSITURA DE AÇÕES}

Cabe explicar que "acompanhamento" supõe diagnóstico de problemas, por meio de estratégias de discussão/reflexão grupal, análise dos problemas em seus determinantes, articulações e implicações, negociação de propostas de mudanças que também serão reavaliadas, ou seja, processo permanente de planejamento participativo, tendo como foco o projeto pedagógico do curso que, durante todo o tempo, deve ser discutido, avaliado e recomposto. É importante ressaltar que, ao longo do tempo, apesar de as articulações com grupos específicos de professores serem necessárias, esse espaço também deve ser compartilhado pelo colegiado de curso, dando potencialidade para a construção da ideia de curso como uma tessitura, organicamente articulado, considerando-se a indissociabilidade de ensino, pesquisa e extensão.

1. O Projeto Político-Pedagógico (PPP) como instrumento de gestão: Implantação/Implementação do PPP e Desenvolvimento do Currículo Acompanhamento do processo de implementação curricular dos cursos de licenciatura em Pedagogia e Química, implantados respectivamente em 2002 e 2003. Ambos os cursos seguiram as orientações dos dispositivos legais específicos, bem como o Programa de Formação de Professores da USP (em fase de elaboração na época) de tal modo que, apesar de suas delimitações, apontam para a construção de currículo integrado, articulando a formação ao mundo do trabalho, à formação básica e específica, aos componentes curriculares básicos e pedagógicos. A docência, a vida na escola e as instituições a ela ligadas, na peculiaridade de seus saberes, valores, metas e práticas cotidianas, foram objetos privilegiados visando à preparação para o exercício profissional e da cidadania na sociedade contemporânea. A formação de professores parte da noção de que a docência não se realiza num quadro abstrato de relações individualizadas de ensino e aprendizagem, mas num complexo contexto social e institucional. As instituições escolares, 
embora em constante e forte diálogo com outras instituições, têm história, valores, saberes e práticas que Ihes são específicos e, nesse sentido, têm um papel social peculiar. Não raramente, essa especificidade tem sido obscurecida pela incorporação e transposição acrítica de teorias, conceitos e perspectivas forjados a partir de interesses alheios à educação como um direito público. Importa, pois, que os princípios que norteiam a formação de professores se voltem para a análise das peculiaridades históricas dessas instituições, de seus agentes sociais e das tarefas.

1.1 Ações: As ações previstas nos cursos de licenciatura em Pedagogia e Química abrangem o acompanhamento do desenvolvimento do currículo em cada ano e por grandes áreas - básica /específica em química, fundamentos da educação e metodologias específicas em pedagogia, revisão e atualização do perfil profissiográfico, conteúdos/competência, articulações já feitas e outras a construir, carga horária, além de outras atividades propostas -, flexibilização curricular, relações com realidade/articulação teoria-prática, estágio curricular supervisionado, tendo em vista que este componente constitui-se eixo formativo e de pesquisa para todos os cursos de licenciatura mencionados.

1.2 Operacionalização: Ao envio anual da estrutura curricular para o Conselho de Graduação, cada curso de licenciatura pode pactuar um cronograma institucional para a realização de oficinas, organizadas por grupos de docentes e alunos (e, quando for possível, pelos demais sujeitos envolvidos - gestores e profissionais de serviços de saúde, escolas de educação profissional, de educação básica e instituições que auxiliem os alunos licenciados e criem espaços formativos e profissionais). Outra ação pode ser planejada, tal como a realização de encontros entre os professores de cada ano para a construção da "matriz" de horários anual e/ou semestral - esse momento deve ultrapassar o cumprimento apenas burocrático dos horários para fomentar espaço reflexivo sobre o currículo como, por exemplo, problematizar, a partir dos horários, a oferta de aulas e atividades aos sábados, até porque uma grande maioria de nossos alunos é formada por trabalhadores; uma situação muito peculiar no Brasil.

\section{Desenvolvimento do processo ensino-aprendizagem em sala de aula e cenários práticos}

2.1 Ações: Acompanhamento do desenvolvimento das atividades de ensino - planejamento das disciplinas - objetivos, conteúdos/competência, metodologia, avaliação, recursos e infraestrutura disponíveis. Nesse eixo, as dificuldades encontradas referem-se à utilização de metodologia crítica problematizadora fundamentada em perspectiva crítica da educação; ao 
enfoque no referencial da competência dialógica; à construção do processo de avaliação formativo e aos embates originados pela concepção de ciência e pela tradição da universidade.

2.2 Operacionalização: Realização de oficinas de trabalho, cursos formativos e/ou reuniões de estudo, realizadas durante o ano, com os docentes e representantes de estudantes com o objetivo de acompanhar a implantação do Projeto Político-Pedagógico do Curso - PPPC, bem como discutir e analisar os programas de "aprendizagem" propostos nas disciplinas. Nesse momento, poderão ser revistas as possibilidades articuladoras de conteúdos e mesmo de processos avaliativos, também oportunizar a troca de experiências sobre métodos e estratégias de ensino empregados em sala de aula. Além dessas atividades, acrescenta-se a parceria com o Grupo de Avaliação do Ensino de Graduação e Comissão de Graduação (CG) e outros grupos institucionais que visam estimular a discussão sobre os instrumentos de avaliação que os docentes vêm adotando nas disciplinas e a possibilidade de elaboração de um instrumento institucional, o que possibilita a busca de informações que subsidiem a avaliação do ensino.

3. Gestão do Ensino: Cabe à Comissão Coordenadora de Cursos (CoC) realizar permanente processo reflexivo sobre o seu próprio trabalho (autoavaliação), reconfigurando ações e modos de atuar na comunidade e internamente no grupo. A intenção é formar um grupo que se constitui no percurso desse processo para coordenar a gestão do curso. É importante que a $\mathrm{CoC}$ mantenha diálogo com a CG a quem assessora e com os departamentos representados pelas chefias, uma vez que nas Unidades da Universidade ainda não existe a cultura do trabalho de gestão pedagógica de curso que será efetivada pela CoC-Licenciatura. Esta nova sistemática contribui para o enfrentamento de conflitos, para a tomada de decisão acerca de ações a serem cumpridas. Isso demandará árduo trabalho político de negociação, com foco na valorização do ensino de graduação. Cabe também, nesse eixo, investir na formação dos docentes da $\mathrm{CoC}$ no âmbito da gestão do ensino, oferecendo condições para que o grupo aprimore seu desempenho. Essa formação construir-se-á continuamente, na medida em que o grupo conseguir realmente estabelecer um trabalho articulado, fundamentado no processo reflexivo sobre o ensino do curso de licenciatura e sobre seu próprio fazer fundamentado nas relações democráticas e participativas.

3.1 Ação: Organização de um trabalho interno do grupo, a "divisão" de responsabilidade em torno do plano de gestão e as interfaces do grupo com a CG, os Departamentos e toda a comunidade das unidades envolvidas. 
3.2 Operacionalização: Os participantes da CoC devem estabelecer uma agenda e um planejamento de ações elencadas de acordo com as prioridades. Além disso, este grupo, mediado pelo coordenador de curso, pode estabelecer um processo de comunicação com a comunidade, de modo que garanta a troca aberta de informações. No início do trabalho das CoCs, deverá ser feita uma reunião com representantes da CG com a finalidade de compartilhar este Plano de gestão, uma vez que a CoC é uma Comissão Assessora da CG. Nesta reunião, pode ser sugerida a elaboração de um fluxo de trabalho para os trâmites cotidianos de gestão do ensino, evitando duplicidade de tarefas e informações. Uma ação fundamental, neste contexto, refere-se ao trabalho de cunho político e articulador com as chefias departamentais, para a apresentação do Plano de gestão e compreensão da proposta de trabalho do grupo, bem como da proposta de fluxo de trabalho elaborado com a CG. Outra ação importante é propor a realização de cursos, palestras e leituras que enfoquem aspectos específicos da gestão de ensino e de outros temas como, por exemplo, os relativos ao projeto pedagógico, ao planejamento do processo ensino-aprendizagem, enfim ao acompanhamento do currículo. Nesse sentido, é essencial a articulação com o Grupo de Apoio Pedagógico do Campus da USP de Ribeirão Preto (GAPRP) ${ }^{1}$, para desenvolver ações e atividades que têm como objetivo incentivar a participação dos docentes universitários nos encontros abertos de discussão sobre os saberes pedagógicos que dizem respeito à docência na universidade.

4. Formação pedagógica do corpo docente: Apesar desse eixo relacionarse também à gestão do ensino, nós o colocamos em destaque, dada sua importância. Investir na formação pedagógica do corpo docente, condição diferencial para promover processos de mudanças na graduação, não é apenas tarefa da $\mathrm{CoC}$, mas como responsável pela gestão pedagógica dos cursos de licenciatura, é importante que as CoCs estimulem a formação docente.

4.1 Ação: Estímulo à formação pedagógica dos docentes do curso de licenciatura.

4.2 Operacionalização: Efetuar o levantamento nos cursos acerca dos docentes que fizeram o Curso Pedagogia Universitária, propondo um encontro com eles para estabelecer uma parceria mais efetiva nos momentos de reuniões pedagógicas entre o "colegiado" de curso. Em parceria com o GAPRP, incentivar a participação dos docentes nos encontros abertos de discussão de temas pedagógicos e propor cursos/palestras, conforme as necessidades específicas. 
A gestão de um curso universitário representa um duplo desafio: de um lado, o acompanhamento e a atualização do PPP, bem como a tomada de decisão acerca das questões que vão surgindo no decorrer do processo; de outro, a agregação de docentes, estudantes e demais colegas gestores visando a um processo de participação democrática. A gestão possibilita a reflexão e participação, requerendo sujeitos mais criativos, participativos e integrados a um projeto de sociedade e de educação universitária que compreende uma pluralidade de exigências, as quais passam pelos saberes disciplinares, culturais, afetivos, técnicos, psicológicos, sociológicos, metodológicos e políticos. A democratização do conhecimento, a competência profissional e as múltiplas dimensões da processualidade docente evidenciam a concepção de gestão como alternativa de abertura às práticas educativas, às práticas sociais integradas.

Apesar de avanços institucionais na universidade seja pelo estabelecimento de um Programa de Formação de Professores ou pela definição do papel que as CoCs devem desempenhar, ressaltamos que temos um longo caminho a percorrer no que concerne à gestão de cursos de graduação na universidade, considerando alguns limites que, neste momento, ainda são considerados desafios. Um desses limites refere-se à multiplicidade de papéis que o professor universitário deve desempenhar no campo do ensino, da pesquisa e da extensão. Por outro lado, no cotidiano da universidade, a comunicação por meio eletrônico impõe aos professores inúmeras demandas, num processo que nem sempre se separam as ações importantes das desnecessárias. Sem dúvida, também esse fato dificulta o processo de gestão.

PEDAGOGICAL MANAGEMENT OF TEACHER FORMATION COURSES AT A PUBLIC UNIVERSITY: CONTRIBUTIONS TO A REFLECTION

ABSTRACT:This paper, a reflection on experiences of coordinating undergraduate teacher formation courses in the context of a public Brazilian university, focuses on what facilitates and limits the building of a collective process where the courses' pedagogical projects are a management tool. Certain legal provisions and teacher training courses focusing on the theme of management, sponsored by the university, are included in what facilitates the process and are then analyzed. Included among the hindrances are difficulties in undertaking collective work, the excessive workload of teachers, the conditions under which undergraduate courses are offered, and the promotion and priority of research at the expense of teaching.

KEYWORDS: Pedagogical Management in Higher Education. Coordination of undergraduate courses. Curriculum. Teacher formation. 


\section{NOTA}

1. O GAPRP/USP, institucionalizado pela Portaria Interna da Pró-Reitoria de Graduação n. 4/2004, foi idealizado pelos presidentes das Comissões de Graduação das Unidades do Campus de Ribeirão Preto/USP, preocupados com a melhoria do ensino, o que vem ao encontro da política de valorização da graduação nesta Universidade, relacionandose às diretrizes políticas nacionais e internacionais voltadas ao ensino superior.

\section{REFERÊNCIAS}

AFONSO, A. J. Reforma do Estado e Políticas Educacionais: alguns tópicos para discussão. Anuário GT Estado e Política Educacional: políticas, gestão e financiamento da educação. In: REUNIÃO ANUAL DA ANPED, 23, Caxambu, 2000. Caxambu: ANPED, 2000, p. 15-36. 1 CD.

BRASIL. Conselho Nacional de Educação. Documento Referência para o Fórum Nacional de Educação Superior. Brasília: CNE, 2009.

BRASIL. Ministério da Educação. Documento síntese do Fórum Nacional de Educação Superior (FNES). Conselho Nacional de Educação. Câmara de Educação Superior. Secretaria de Educação Superior. Brasília: MEC/CNE/SESU, 2009.

BRASIL. Conselho Nacional de Educação. Portarias CNE/CP n. 7/2009 e n. 8/2009, aprovado por unanimidade na sessão plenária do dia 4 de agosto de 2009, contendo "Indicações para subsidiar a construção do Plano Nacional de Educação 2011 - 2020". Brasília: CNE, 2009.

BRASIL. Ministério da Educação. Documento Referência da CONAE. Brasília: MEC/ SESU, 2009.

BRASIL. Lei n. 9394, de 20 de dezembro de 1996. Estabelece as Diretrizes e Bases da Educação Nacional. Brasília: Senado Federal, 1996.

BRASIL. Ministério da Educação. Sinopse Estatística da Educação Básica. Censo escolar 2006. Brasília: INEP, 2007.

BRASIL. Lei n. 10.172, de 9 de janeiro de 2001. Plano Nacional de Educação. Brasília: MEC, 2001.

BRASIL. Ministério da Educação. Plano Nacional de Graduação. Brasília: MEC, 1999.

BRUNO, L. Poder e administração no capitalismo contemporâneo. 4. ed. In: OLIVEIRA, D. A. (Org.). Gestão Democrática da Educação. Petrópolis: Vozes, 2002.

CUNHA, M. I. Inovações Pedagógicas: o desafio da reconfiguração de saberes na docência universitária. In: PIMENTA, S.; ALMEIDA, M. I. Pedagogia Universitária. São Paulo: EDUSP, 2009.

CHAUÍ, M. A universidade pública sob nova perspectiva. In: REUNIÃO ANUAL DA ANPED, 26, 2003, Poços de Caldas. Anais. Poços de Caldas: ANPED, 2003. 1 CD. 
CURY, C. R. J. Por um Plano Nacional de Educação: Nacional, Federativo, Democrático e Efetivo. Texto elaborado para o Conselho Pleno do Conselho Nacional de Educação, em março de 2009. Disponível em: http://portal.mec.gov.br/dmdocuments/pne_200809. pdf > . Acesso em: jun. de 2010.

DALE, R. Globalization and education: demonstrating a common world educational culture or locating a globally structured educational agenda? Educational Theory, $v$. 50, n.4, p. 427-448, 1999.

DELANTY, G. Challenging Knowledge: the university in the knowledge society. Londres: Society for Research Into Higher Educat Press, 2001.

Declaração da Conferência Regional de Educação Superior na América Latina e no Caribe (CRES). Cartagena de Índias, 2008.

FERREIRA, N. S. A gestão de educação e as políticas de formação de profissionais da educação: desafios e compromissos. In: FERREIRA, NSC. (Org.). Gestão democrática da educação: atuais tendências, novos desafios. 5. ed. Petrópolis: Vozes, 2006.

FRIGOTTO, G.; CIAVATTA, M. (Orgs.). Teoria e educação no labirinto do capital. Petrópolis: Vozes, 2001.

LÜCK, H. Gestão Educacional. 5. ed. Petrópolis: Vozes, 2010.

MOROSINI, M. C.; MOROSINI, L. Pedagogia Universitária: entre a convergência e a divergência na busca do alomorfismo. UNIrevista, São Leopoldo, v.1, n. 2, p. 1-10, 2006.

NEAVE, G. On the cultivation of quality, efficiency and enterprise: an overview of recent trends in higher education in Western Europe. 1986 - 1988. European Journal of Education, v. 23, n. 1/2, p. 7-23, 1999.

SABADIA, J.A.B. O papel da coordenação de curso: a experiência no ensino de graduação em geologia na Universidade Federal do Ceará, Fortaleza. Revista de Geologia, v. 11, p. 23-29, 1998.

SANTOS, B. S. (Org.). A globalização e as ciências sociais. 3. ed. São Paulo: Cortez, 2004.

SGUISSARDI, V. A universidade neoprofissional, heterônoma e competitiva. In: REUNIÃO NACIONAL DA ANPED, 24, Poços de Caldas, 2004. Rio de Janeiro: D,P \& A.,2004. $1 \mathrm{CD}$.

UNIVERSIDADE DE SÃO PAULO. Pró-Reitoria de Graduação. Comissão Permanente dos Cursos de Licenciatura. Programa de Formação de Professores da USP. São Paulo: USP, 2004.

. Pró-Reitoria de Graduação, Resolução CoG n. 5500. Estabelece normas para o funcionamento das Comissões de Coordenação de Cursos. São Paulo: USP, 2009.

VEIGA, I. P. A. (Org.). As dimensões do Projeto Político-Pedagógico. Campinas: Papirus, 2001.

ZABALZA, M. A. O ensino universitário: seu cenário e seus protagonistas. Porto Alegre: Artmed, 2004. 
Gláucia Maria da Silva é Professora doutora do Departamento de Química da Faculdade de Filosofia, Ciências e Letras da USP de Ribeirão Preto.

E-mail: slauciams@ffclrp.usp.br

Noel Prestes Padilha Rivas é Professora doutora do Departamento de Psicologia e Educação da Faculdade de Filosofia, Ciências e Letras da USP de Ribeirão Preto.

E-mail: noerivas@ffclrp.usp.br 